\title{
Polymer-functionalized silica nanoparticles for improving water flood sweep efficiency in Berea sandstones
}

\author{
Alberto Bila ${ }^{1, * i D}$, Jan Åge Stensen ${ }^{1,2}$, and Ole Torsæter ${ }^{1}$ (D) \\ ${ }^{1}$ PoreLab Research Center, Department of Geoscience and Petroleum-Norwegian University of Science and Technology (NTNU), S. P. \\ Andersens veg 15a, 7031, Norway \\ ${ }^{2}$ Sintef Industry, S. P. Andersens veg 15a, 7031, Norway
}

\begin{abstract}
Extraction of oil trapped after primary and secondary oil production stages still poses many challenges in the oil industry. Therefore, innovative enhanced oil recovery (EOR) technologies are required to run the production more economically. Recent advances suggest renewed application of surfacefunctionalized nanoparticles (NPs) for oil recovery due to improved stability and solubility, stabilization of emulsions, and low retention on porous media. The improved surface properties make the NPs more appropriate to improve microscopic sweep efficiency of water flood compared to bare nanoparticles, especially in challenging reservoirs. However, the EOR mechanisms of NPs are not well understood. This work evaluates the effect of four types of polymer-functionalized silica NPs as additives to the injection water for EOR. The NPs were examined as tertiary recovery agents in water-wet Berea sandstone rocks at $60{ }^{\circ} \mathrm{C}$. The NPs were diluted to $0.1 \mathrm{wt}$. \% in seawater before injection. Crude oil was obtained from North Sea field. The transport of NPs though porous media, as well as nanoparticles interactions with the rock system, were investigated to reveal possible EOR mechanisms. The experimental results showed that functionalized-silica NPs can effectively increase oil recovery in water-flooded reservoirs. The incremental oil recovery was up to $14 \%$ of original oil in place (OOIP). Displacement studies suggested that oil recovery was affected by both interfacial tension reduction and wettability modification, however, the microscopic flow diversion due to pore plugging (log-jamming) and the formation of nanoparticle-stabilized emulsions were likely the relevant explanations for the mobilization of residual oil.
\end{abstract}

\section{Introduction}

Oil production rates from existing fields are declining, and the occurrence of new discoveries has been scarce [1, 2]. Therefore, improving the recovery rates from mature oil fields is a priority for oil companies. The oil recovery factor from oil fields is typically around $20-40 \%$ of OOIP [3], the remaining oil is in some cases amenable for EOR. After conventional secondary water flooding, residual oil dwells in the reservoir pores as capillary-trapped and/or by-passed oil $[2,4]$. Mobilization of the capillary-trapped oil requires increasing the viscous forces or decreasing the capillary forces [4, 5]. Applying sufficient pressure gradients between wells when injecting viscous fluid to increase viscous forces is the major challenge [2], as it can fracture the reservoir; hence, decreasing the capillary forces becomes an assertive option. This can be achieved through the reduction of interfacial tension (IFT) between the reservoir fluids. The by-passed oil or the oil located in unswept areas of the reservoir can be mobilized by pore plugging and flow diversion of injectants [4-7].

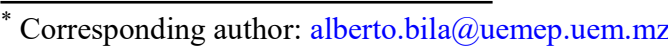

To this end, research suggests that properly designed nanoparticles (NPs) can change the physical or chemical behavior of an oil reservoir, thereby improving microscopic sweep efficiency of water flood. This is because NPs have small diameter size (1-100 nm) and large surface area-to-volume ratio. These properties enhance the mobility and surface activity of NPs, particularly at high temperature, making them suitable to modify fluid-rock properties and increase oil recovery [8, 9]. Furthermore, NPs can easily travel through and reach untouched zones of a reservoir with no severe impact to the rock permeability $[1,7,9]$.

Thus far, silica NPs are the most researched nanomaterials because of their natural occurrence in sandstone formations and low cost $[1,10]$. Additionally, silica NPs can be synthesized and surface functionalized to meet particular reservoir conditions [8, 9]. Promising oil recovery results have been reported in the literature due to silica nanoparticles injection [10-17] under a variety of experimental conditions. That is, the use of silica NPs of variable size, composition, surface functionalities, etc., 
suspended in aqueous solutions with diverse ionic strength [10-16] or in non-aqueous solutions [15]. The concentration of the NPs in the base fluid is also varied including injection flowrate, temperature, evaluation criteria of oil recovery, etc. This, in turn, makes it difficult to adequately grasp the oil recovery mechanisms of silica nanoparticles. Aside from i) IFT reduction and wettability alteration, which are the two most suggested mechanisms $[11,15,16,18]$, NPs improve oil recovery by ii) structural disjoining pressure [26], iii) formation of emulsions [1921], and iv) log-jamming effect [5-7, 13, 22-24]. In some circumstances, more than one mechanism is associated with oil recovery.

The shortcoming of using typical NPs is associated to their aggregation and agglomeration, especially at harsh reservoir conditions. Therefore, recent advances suggest renewed application of surface-functionalized NPs for EOR to overcome some of the problems encountered with bare nanoparticles. Silica NPs, which have polymers covalently attached to its surface forms a new class of nanomaterials that may be superior to bare NPs for EOR due to improved properties such stability, stabilization of emulsions, low retention on porous media, etc. [25, 26]. These are known as polymer-functionalized/coated NPs. Few studies on their application for EOR have shown to be suitable for reservoir conditions [27]. Ponnapati, et al. [28] conducted injection experiments with polymergrafted silica NPs in Berea sandstone. The NPs could mobilize residual oil and yield $7.9 \%$ of OOIP. The authors speculated that NPs clog the pores and increase local pore pressure to remove oil trapped in larger pores. Behzadi and Mohammadi [29] reported that polymer-coated silica NPs can modulate oil and water IFT and change the wettability of the oil-wet glass micromodel to more waterwet, resulting in higher EOR than unmodified silica nanoparticles. Experiments conducted by Choi, et al. [30] found that, when injecting polymer-coated silica NPs into water-wet sandstones, $74.1 \%$ oil was recovered, which was comparable to water flood $(68.9 \%)$ and $72.7 \%$ of OOIP from unmodified NPs. The authors argued that modified silica NPs increased oil recovery by lowering the injection pressure relative to unmodified ones, which was associated to the ordering of NPs in the wedge film between oil and rock surface, rendering more hydrophilic surface. Recently, Bila, et al. [17] evaluated various polymer-coated silica NPs for EOR application in neutralwet cores. The authors reported an incremental oil recovery up to $5.2 \%$ of OOIP after water flood. Like Choi, et al. [30], they reported pressure decrease with NPs injection. The oil recovery was attributed to the interfacial tension reduction and wettability alteration to more waterwet condition.

Based on the above studies, polymer-functionalized NPs can offer a pathway for EOR, however, more studies are needed to improve understanding of the underlying EOR mechanisms. This work evaluated the efficacy of polymer-functionalized silica NPs for EOR in water-wet reservoirs and identified the main mechanisms. Flood tests were conducted at high temperature with nanofluids prepared at $0.1 \mathrm{wt} . \%$ synthetic seawater.

\section{Experimental materials}

\subsection{Silica NPs and synthetic seawater}

Four types of silica NPs were used. The particles were spherical and hydrophilic with surface functionalized with polymer molecules. The polymer coating aimed at providing a protective layer to the NPs and to prevent the NPs from attracting each other in solution (i.e. steric repulsive forces). These NPs are referred to as polymerfunctionalized/coated silica nanoparticles hereafter. The main component of the NPs was silicon dioxide, other components such as aluminum oxide $\left(\mathrm{Al}_{2} \mathrm{O}_{3}\right)$ and mixed oxides (MOX) were present. The NPs are special research and development $(\mathrm{R} \& \mathrm{D})$ products from Evonik Industries and were supplied to us as AERODISP $^{\circledR}$, which is AEROSIL ${ }^{\circledR}$ particles in liquid solution. The properties of the NPs suspended in distilled water, as received, are given in Table 1.

Table 1. Properties of silica NPs dispersed in distilled water.

\begin{tabular}{|r|l|c|c|}
\hline NF & \multicolumn{1}{|c|}{ Basis } & wt. \% & Size $(\mathrm{nm})$ \\
\hline $02-3$ & $\mathrm{SiO}_{2}$ (sol gel cationic) & 38.6 & 107 \\
\hline $02-4$ & $\mathrm{SiO}_{2}$ (sol gel anionic) & 26.0 & 32 \\
\hline $02-6$ & $\mathrm{SiO}_{2} / \mathrm{Al}_{2} \mathrm{O}_{3} / \mathrm{MOX}$ & 21.6 & 218 \\
\hline $02-8$ & $\mathrm{SiO}_{2} / \mathrm{Al}_{2} \mathrm{O}_{3} / \mathrm{MOX}$ & 25.6 & 145 \\
\hline
\end{tabular}

The concentrated solutions of the NPs were diluted to 0.1 wt. \% in synthetic North seawater (SSW), here referred to as nanofluid (NF). The number is used to identify the nanofluid type. The composition of prepared SSW by wt. \% was $\mathrm{NaCl}(74.4), \mathrm{KCl}(1.85), \mathrm{NaHCO}_{3}$ (0.57), $\mathrm{Na}_{2} \mathrm{SO}_{4}$ (10.62), $\mathrm{CaCl}_{2} \cdot 6 \mathrm{H}_{2} \mathrm{O}$ (4.24), $\mathrm{MgCl}_{2} \cdot 6 \mathrm{H}_{2} \mathrm{O}$ (8.25) and $\mathrm{Sr}_{2} \cdot 6 \mathrm{H}_{2} \mathrm{O}(0.07)$. The total dissolved salts were $\approx 38,318 \mathrm{ppm}$. The density, viscosity and $\mathrm{pH}$ of SSW was $1.008 \mathrm{~g} / \mathrm{cm}^{3}, 0.53 \mathrm{cP}$ and 7.97 , respectively. The nanofluid density was $1.007-1.009 \mathrm{~g} / \mathrm{cm}^{3}$ and the viscosity ranged from $0.51-0.67 \mathrm{cP}$. All measurements were performed at $60{ }^{\circ} \mathrm{C}$ using Anton Paar Density meter and Anton Paar Rheometer, respectively.

\subsection{Oleic phase}

A North Sea reservoir crude oil was used in this work. It was a light oil $\left(30^{\circ} \mathrm{API}, 6 \mathrm{cP}\right.$ at $\left.60{ }^{\circ} \mathrm{C}\right)$ with 71.57 wt. $\%$ saturates, 20.81 wt. $\%$ aromatics, 7.44 wt. $\%$ resins and 0.18 wt. $\%$ of asphaltenes. The crude oil was filtered twice through a 5- $\mu \mathrm{m}$ Millipore filter to remove any suspended particles that can block the lines and the pores spaces and or change the oil composition. Normal decane with density of $0.73 \mathrm{~g} / \mathrm{cm}^{3}$ and viscosity of $0.92 \mathrm{cP}$ at $20^{\circ} \mathrm{C}$ was used for wettability experiments. 


\subsection{Core characterization and preparation}

Ten core plugs initially at water-wet conditions were used in this work. The cores were drilled from the same block of Berea sandstone; their mineral composition was measured with X-ray diffraction and were composed of 93.7 vol \% quartz, 5 vol \% of Microcline (Alkali feldspar) and $1.3 \mathrm{vol} \%$ Diopside. The core plugs were prepared to have similar dimensions of $3.8 \mathrm{~cm}$ diameter and length of $10 \mathrm{~cm}$. They were cleaned with methanol through Soxhlet extractor and then dried at $60^{\circ} \mathrm{C}$ for 2-3 days. Afterwards, gas porosity and permeability were measured on dried core plugs. The next step was to evacuate the core plugs for 2 hours and saturate them with SSW at 100 mbar vacuum pressure for 2-3 hours. The saturated cores were left soaked in the same SSW for at least 10 days for ionic equilibration with the rock constituents. The weight of the wet and dried core plugs was used to calculate the porosity and pore volume (PV), and these data are given Table 2.

Table 2. Properties of Berea sandstone core plugs.

\begin{tabular}{|c|c|c|c|}
\hline Core & Porosity (\%) & Kabs $^{1} \mathbf{( m D )}$ & PV (ml) \\
\hline L1 & 18.7 & 404 & 21.4 \\
\hline L2 & 17.4 & 537 & 21.8 \\
\hline L3 & 15.9 & 460 & 17.6 \\
\hline L4 & 16.2 & 411 & 17.9 \\
\hline L5 & 17.1 & 367 & 18.9 \\
\hline L6 & 16.8 & 333 & 18.5 \\
\hline L7 & 18.4 & 384 & 20.3 \\
\hline L8 & 18.3 & 184 & 20.3 \\
\hline
\end{tabular}

${ }^{1}$ Klinkenberg corrected permeability.

\subsection{Core flooding equipment}

Fig. 1 presents a schematic of core flooding rig with its main components labelled. It utilizes an injection pump, three cylinders containing oil, synthetic sea water and nanofluid each. All cylinders were assembled vertically inside a temperature-controlled oven.

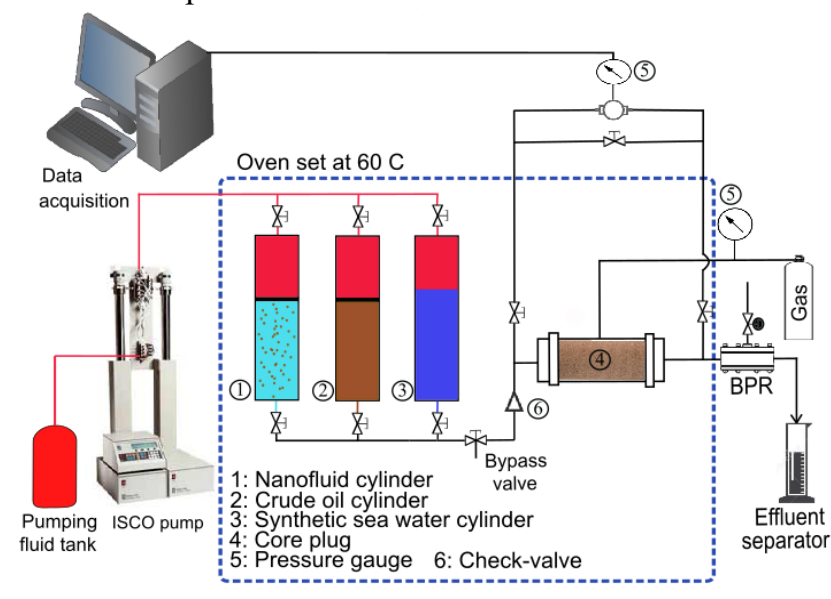

Fig. 1. Schematic of core flooding apparatus.

The core was loaded in the core-holder and oriented horizontally at a confining pressure held within 18-22 bar.
A check valve and a backpressure regulator (BPR) were used to prevent back-flow of produced fluids and maintain the pore pressure constant during the core flooding experiments. The BPR wrapped with a heating plate was set to 5-bar pressure. The flooding experiments were conducted at $60{ }^{\circ} \mathrm{C}$ with the core oriented horizontally.

\section{Experimental methodology}

\subsection{Core flooding}

Eight flooding tests were conducted with nanofluids as tertiary EOR-agents (parallel tests). First, the 100\% SSW saturated core plug was injected with fresh SSW for 1-2 PVs to ensure a complete removal of gas bubbles. Second, the drainage process was conducted by successively increasing the crude oil injection flowrate $(0.5,1.5$ to 3 $\mathrm{ml} / \mathrm{min}$ ) for $15 \mathrm{PVs}$. This procedure ensured that there was no SSW production and the irreducible water saturation $\left(\mathrm{S}_{\mathrm{wir}}\right)$ was achieved. The direction of the injection was reversed after half of the total PVs to even the distribution of the fluids in the core. This procedure also established the OOIP reported in Table 3. It is worth note that the drainage step was conducted at ambient conditions.

Before the experiments, the flooding system was heated while injecting crude oil at low rate of $0.02 \mathrm{ml} / \mathrm{min}$ until the temperature stabilized at $60{ }^{\circ} \mathrm{C}$. Then, water (SSW) flood followed at constant flowrate of $0.2 \mathrm{ml} / \mathrm{min}$ until there was no oil production for 1-2 PVs. Thereafter, the flowrate was increased ten-fold (bump rate) for $\approx 1 \mathrm{PV}$ to overcome the capillary end-effects. In the following step, the injection was continued with nanofluid at 0.2 $\mathrm{ml} / \mathrm{min}$ until there was no more oil production for $2-4$ PVs. Then, the flowrate was bumped for $\approx 1 P V$. During the flood experiments, produced oil was collected every $1 / 4 \mathrm{PV}$ and corrected for the flooding system dead volume. When the production was occurring at low pace, a camera with automated capturing was used to record the production in a graded line over time, while the total volume was being collected in a large effluent separator. The recorded pictures were then analyzed to measure the amount of oil produced. This oil was compared to the total volume of oil produced in the large effluent separator. The differential pressure $(\mathrm{dP})$ and oil recovery were recorded versus PVs injected, and the residual oil saturation $\left(\mathrm{S}_{\mathrm{or}}\right)$ was calculated for each flooding stage.

\subsection{Interfacial tension measurement}

The interfacial tension (IFT) between crude oil and SSW or nanofluids was determined with pendant drop and spinning drop techniques at $60^{\circ} \mathrm{C}$. For the pendant drop method, Kruss drop shape analyzer 100 assembled with a J-shape syringe-needle of $1.0047 \mathrm{~mm}$ of inner diameter was used to dose the oil drops. With the oil drop hanging from the needle in the bulk phase, the measurements were taken every 20 seconds until static IFT value was reached. 
The IFT was calculate using Young-Laplace model. For the spinning drop method, a SVT20N (Data Physics) spinning video tensiometer was used.

\subsection{Amott-wettability test}

Wettability of the cores was evaluated before and after nanofluid flooding at ambient conditions using Amotttest. Each core plug was set at $S_{\text {wir }}$ before placing it in the Amott cell filled with SSW. The SSW was allowed to imbibe spontaneously into the core displacing oil over time. The oil production was recorded stepwise until the equilibrium was reached and the total amount denoted as $\mathrm{V}_{\mathrm{ol}}$. The remaining mobile oil $\left(\mathrm{V}_{\mathrm{o} 2}\right)$ was forcibly displaced by core flooding method, i.e. by injecting SSW at high flowrates $(1-3 \mathrm{ml} / \mathrm{min})$. Then, the core was removed from the core-holder and dipped in the Amott cell filled with oil to assess whether the oil could spontaneously displace water phase. At equilibrium, the amount of SSW produced was recorded as $\mathrm{V}_{\mathrm{wl}}$. The remaining mobile SSW in the core $\left(\mathrm{V}_{\mathrm{w} 2}\right)$ was displaced by injecting oil at high flowrates. The oleic phase was $n$ decane.

The wettability index (WI) was is the difference between the displacement-by-water ratio (water index, $\left.\mathrm{I}_{\mathrm{w}}=\mathrm{V}_{\mathrm{o} 1} /\left(\mathrm{V}_{\mathrm{o} 1}+\mathrm{V}_{\mathrm{o} 2}\right)\right)$ and displacement-by-oil ratio (oil index, $\left.\mathrm{I}_{\mathrm{o}}=\mathrm{V}_{\mathrm{w} 1} /\left(\mathrm{V}_{\mathrm{w} 1}+\mathrm{V}_{\mathrm{w} 2}\right)\right)$. A Categorization of wettability based on WIs is given by ref. [31].

\section{Experimental results}

\subsection{Oil recovery}

Eight core flood tests were conducted at $60^{\circ} \mathrm{C}$. Two core plugs were used for each nanofluid type to reproduce the results and reduce experimental errors. To overcome the capillary end-effects and ensure that any additional oil recovery was a result of nanofluid effect, the flow rate was increased from 0.2 to $2 \mathrm{ml} / \mathrm{min}$ at the end of the floods (procedure described in section 3.1). The oil recoveries achieved by water flood varied from 47.2 to $56.1 \%$ of OOIP. The incremental oil recovery due to nanofluid flooding ranged from 7.0 to $14 \%$ of OOIP. The production of first oil due to nanofluid injection was occurred from 1.5 to 4 PVs. This was found to depend on NP type, and it was also affected by core properties. Significant oil production was observed after injection of several PVs of nanofluid. An example of oil recovery profile (water and nanofluid flood) at low- and high flow-rates is given in Fig. 2 as function of PVs (for NF02-4 and NF02-6). Crude oil was produced as an oil-in-water emulsion, especially when the flowrate was increased, during the flood of nanofluids NF02-3 and NF02-4. These samples (NF02-3 and NF02-4) could increase oil recovery without having significant effect on the injection pressure relative to the base case, i.e. the differential pressure remained at the level of water flood (see Fig. 7a) throughout the duration of the process.
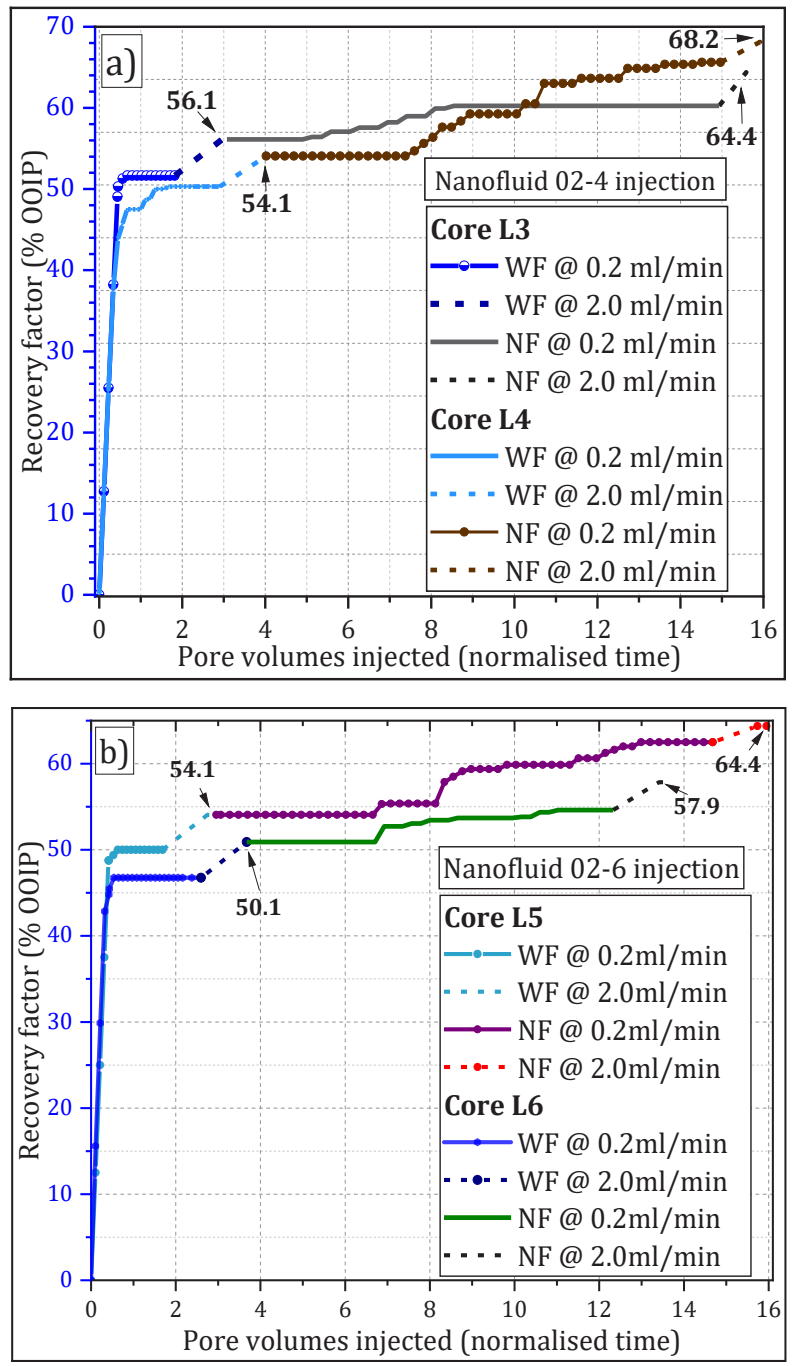

Fig. 2. Oil recovery factors (RFs) versus PVs injected: a) NF024 and, b) NF02-6 injection. In both cases, the first oil production was observed after $3 \mathrm{PVs}$ of nanofluids injection.

In contrast, injection of NF02-6 and NF02-8 significantly increased water flood pressure (see Fig. 7b); no visible signs of formation of emulsions were observed, even when the flowrate was increased. At the end of the flooding, a filtered NP "cake" was observed at the core inlet for both NF02-6 and NF02-8, showing physical filtration of large NPs and plugging of the pores during the floods. Table 3 summarizes the main results used to evaluate the nanofluid samples. 
Table 3. Oil recovery factors (expressed as \% of OOIP) achieved at each injection rate. The $\mathrm{RF}_{1}$ and $\mathrm{RF}_{2}$ represent the oil recovery factors at low flowrate $(0.2 \mathrm{ml} / \mathrm{min})$ and high flowrate $(2 \mathrm{ml} / \mathrm{min})$, respectively.

\begin{tabular}{|c|c|c|c|c|c|c|c|c|c|c|c|c|c|}
\hline \multirow{2}{*}{$\mathrm{NF}$} & \multirow{2}{*}{ Core } & \multirow{2}{*}{$\begin{array}{l}S_{\text {wir }} \\
(\%)\end{array}$} & \multirow{2}{*}{$\begin{array}{c}\text { OOIP } \\
(\mathrm{ml})\end{array}$} & \multicolumn{3}{|c|}{ Water flooding } & \multirow{2}{*}{$\begin{array}{l}S_{\text {or } 1} \\
(\%)\end{array}$} & \multicolumn{3}{|c|}{ Nanofluid flooding } & \multirow{2}{*}{$\begin{array}{l}S_{\text {or2 }} \\
(\%)\end{array}$} & \multirow{2}{*}{$\begin{array}{l}E_{D} \\
(\%)\end{array}$} & \multirow{2}{*}{$\begin{array}{c}\text { Total } \\
\text { RF }\end{array}$} \\
\hline & & & & $\mathrm{RF}_{1}$ & $\mathrm{RF}_{2}$ & $\mathrm{RF}_{\mathrm{t}}$ & & $\mathrm{RF}_{1}$ & $\mathrm{RF}_{2}$ & RF & & & \\
\hline \multirow{2}{*}{$02-3$} & L1 & 24.7 & 16.1 & 44.7 & 2.5 & 47.2 & 39.8 & 8.6 & 1.4 & 9.9 & 33.6 & 15.6 & 57.1 \\
\hline & L2 & 32.2 & 14.8 & 43.9 & 4.1 & 48.0 & 35.3 & 7.0 & 4.1 & 11.1 & 27.7 & 22.0 & 59.1 \\
\hline \multirow{2}{*}{$02-4$} & L3 & 10.5 & 15.7 & 51.7 & 4.4 & 56.1 & 39.3 & 15.3 & 3.0 & 8.3 & 31.9 & 19.0 & 64.4 \\
\hline & L4 & 10.6 & 16.0 & 50.3 & 3.8 & 54.1 & 41.1 & 11.6 & 2.5 & 14.1 & 28.5 & 31.0 & 68.2 \\
\hline \multirow{2}{*}{$02-6$} & L5 & 15.5 & 16.0 & 50.0 & 4.1 & 54.1 & 38.8 & 8.4 & 1.9 & 10.3 & 30.1 & 22.4 & 64.4 \\
\hline & L6 & 16.7 & 15.4 & 46.8 & 4.2 & 51.0 & 44.3 & 4.7 & 2.3 & 7.0 & 35.1 & 21.0 & 58.0 \\
\hline \multirow{2}{*}{$02-8$} & L7 & 18.8 & 16.5 & 49.4 & 4.2 & 53.6 & 37.7 & 8.2 & 0.9 & 9.1 & 30.0 & 20.4 & 62.7 \\
\hline & L8 & 18.7 & 16.5 & 52.4 & 2.7 & 55.2 & 36.5 & 7.3 & 3.0 & 10.3 & 28.1 & 23.0 & 65.5 \\
\hline
\end{tabular}

The oil displacement efficiency was evaluated by equation:

$$
\mathrm{E}_{D}=\left[1-\left(\frac{\mathrm{S}_{\mathrm{or} 2}}{\mathrm{~S}_{\mathrm{or} 1}}\right)\right] \times 100 \%
$$

Here, $\mathrm{S}_{\mathrm{or}_{1}}$ and $\mathrm{S}_{\mathrm{or}_{2}}$ represent residual oil saturation at the end of water- and nanofluid-flooding (including low and high flowrate injection), respectively.

\subsection{Interfacial tension}

The interfacial tension (IFT) between crude oil and NF023 and NF02-4 was measured with both pendant drop and spinning drop methods. Nanofluids NF02-6 and NF02-8 were very sensitive at high temperature; the solutions immediately precipitated at $60{ }^{\circ} \mathrm{C}$ and became opaque, thus making it impossible to use the pendant drop method for IFT analysis. The spinning drop was used instead. Fig. 3 shows a crude oil drop hanging from a needle within solution of sample NF02-6. Increasing temperature from at $22{ }^{\circ} \mathrm{C}$ (Fig. 3a) to $60{ }^{\circ} \mathrm{C}$ (Fig. 3b) caused the NPs to self-assemble at the oil and water $(\mathrm{o} / \mathrm{w})$ interface. The formed layers of NPs at the interafce eventually settled to the bottom of the cuvette due to gravity force.
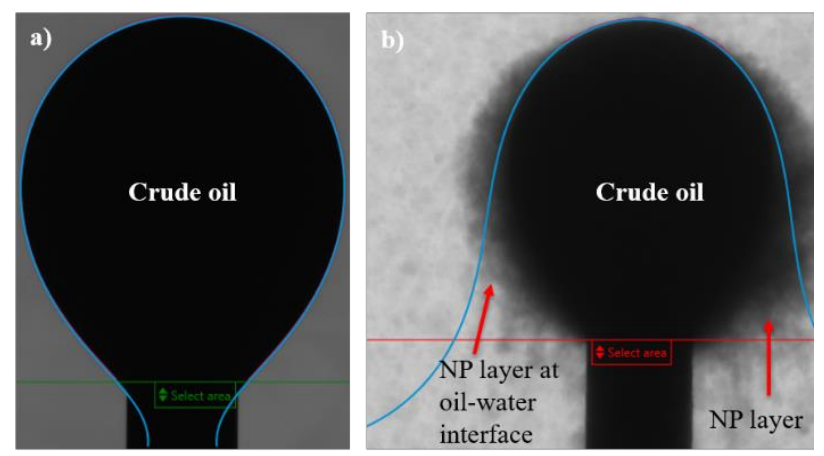

Fig. 3. Crude oil drop suspended from a needle in NF02-6: a) at $22^{\circ} \mathrm{C}$, and b) at $60{ }^{\circ} \mathrm{C}$, NPs self-assembled at the w/o interface.

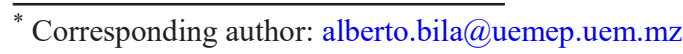

This phenomenon was viewed thanks to high-resolution pendant drop camera. The measured values of IFT are presented in Table 4.

Table 4. Interfacial tension values measured at $60{ }^{\circ} \mathrm{C}$.

\begin{tabular}{|l|c|c|}
\hline \multirow{2}{*}{ Fluid } & \multicolumn{2}{|c|}{ Interfacial tension $(\mathbf{m N} / \mathbf{m})$} \\
\cline { 2 - 3 } & Pendant drop & Spinning drop \\
\hline SSW & 11.0 & 10.0 \\
\hline NF02-3 & 3.5 & 3.1 \\
\hline NF02-4 & 3.3 & 2.9 \\
\hline NF02-6 & - & 6.8 \\
\hline NF02-8 & - & 4.7 \\
\hline
\end{tabular}

The spinning drop was also used to confirm the IFT values obtained from pendant drop method for samples NF02-3 and NF02-4. Fig. 4 shows a crude oil droplet dipped in the capillary tube and spun at 7,000 rpm and at $60^{\circ} \mathrm{C}$. Due to the high rotational speed, there were no visible aggregates of NPs and the IFT could be measured for all samples.

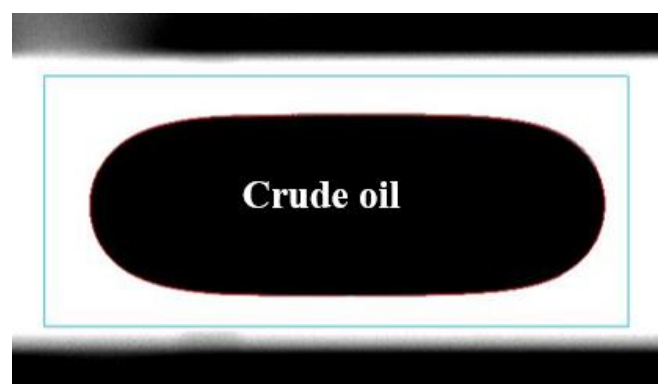

Fig. 4. Shape of the crude oil drop inside the capillary tube filled with NF02-6 and spun at 7,000 rpm for IFT analysis using STV20 spinning drop video tensiometer.

\subsection{Core wettability}

Initial wettability of the cores was evaluated using two reference cores. The average wettability index was, WI = 0.86 , indicating strongly water-wet condition. The cores used afterwards were considered water-wet. This assumption was made because all core plugs were drilled 
from the same block and followed the same preparation procedures. After nanofluid flooding was completed, each core (at $\mathrm{S}_{\text {or }}$ ) was flooded with $n$-decane at high flowrates (1-3 $\mathrm{ml} / \mathrm{min}$ ) until residual water saturation was achieved. Afterwards, the core was dipped into the Amott cell following the procedure described in section 3.3. Fig. 5 shows oil recovery from SSW spontaneous imbibition (SI) during 30-days test. As shown in Fig. 5, the rate of water imbibition decreased slightly in NP treated cores compared with that in original ones (not injected with NPs). Initially, oil was produced from all faces of the core plugs. After 24 hours, the production declined, and it was

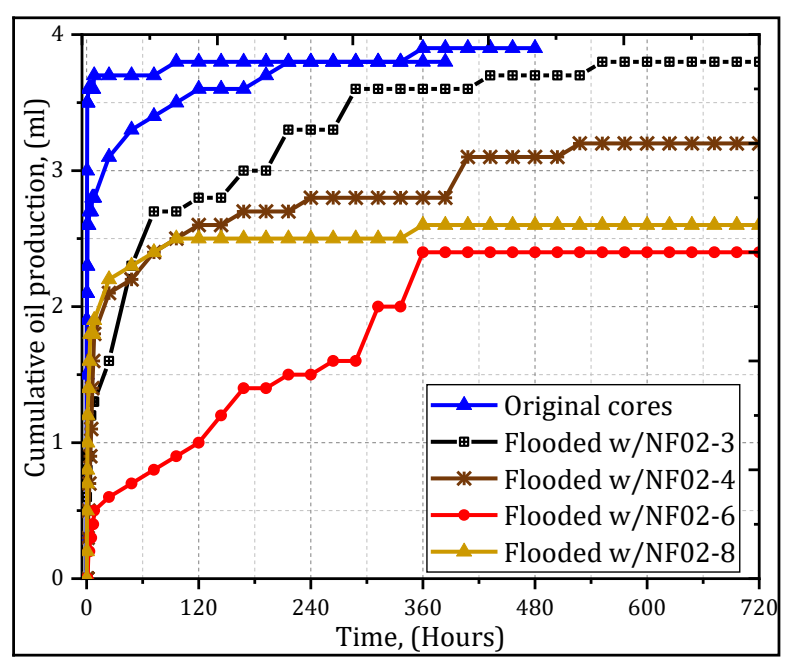

Fig. 5. Water spontaneous imbibition performed on cores flooded with nanofluids (at ambient conditions).

occurring from the top. The produced oil remained on the top surface of the cores and detached from it after several days or by gently shaking the Amott cells. These events are depicted by sudden increase in oil recovery at some points in Fig. 5. At equilibrium, the measured water indexes $\left(\mathrm{I}_{\mathrm{w}}\right)$ varied from 0.5 to 0.89 . In the second cycle of spontaneous imbibition, oil did not imbibe into the core or displace water, implying that Amott oil index is zero, $\mathrm{I}_{\mathrm{o}}=0$. Therefore, the Amott-test was not completed, and Amott water indexes were used to assess the effect of NPs on the rock surface.

\subsection{Permeability and porosity}

After nanofluid flooding, the cores were cleaned with toluene and methanol for several days with Soxhlet extraction and dried at $60{ }^{\circ} \mathrm{C}$ for $2-3$ days. Then, the gas permeability and porosity were measured. The results are presented in Table 5. The objective was to determine and quantify the changes of initial values of permeability and porosity as result of NPs adsorption or retention during nanofluid flood. In Table $\mathbf{5}$ negative values indicate permeability or porosity impairment.

\section{Discussion of the results}

\subsection{Nanofluid stability analysis}

The stability of nanofluids at $0.1 \mathrm{wt} . \%$ was analyzed via: i) particle size distribution (PSD), ii) zeta potential, and iii) sedimentation rates of nanoparticles.

Malvern Zetasizer instrument was used to obtain PSD and zeta potential of NP solutions. After setting the temperature at $60{ }^{\circ} \mathrm{C}$, the average particle diameter size for NF02-3 was $94 \mathrm{~nm}$ and $32 \mathrm{~nm}$ for NF02-4. These values are within the range claimed by manufacturer (i.e. $107 \mathrm{~nm}$ for NF02-3 and $32 \mathrm{~nm}$ for NF02-4), which suggest that NPs were stable in seawater solution, at least for the measured period. The measurements of the particle size for samples NF02-6 and NF02-8 resulted in high values of polydispersity index, suggesting growth of particle size. It was therefore not suitable to characterize the particle size with dynamic light scattering technique. Measurements of zeta potential of NPs gave unreliable values, for unknown reasons.

An analysis of sedimentation rate of NPs was conducted to verify particle size measurements. To this end, nanofluids were placed in the oven at $60{ }^{\circ} \mathrm{C}$ and monitored daily. It was observed that samples NF02-6 and NF02-8 were rapidly rendered unstable at $60^{\circ} \mathrm{C}$, which is consistent with observation made while measuring the IFT. Large NPs structures were formed and deposited to the bottom of the ampules within one-hour storage time. Stability of nanofluids "NF02-3" and "NF02-4" was achieved for up to four days. After this storage-time, they also started to precipitate and gradually settling out of solution, forming large aggregates. Fig. 6 shows NPs in the aggregated form at the bottom of the ampules (white). Interesting that some polymers were seen flocculating in NF02-4 solution. The precipitation of polymers is thought to be due to the divalent cations in aqueous solution (e.g. $\mathrm{Mg}^{2+}, \mathrm{Ca}^{2+}$ ) and high temperature [26, 32]. Consequently, the desired repulsion forces between the NPs in the solution vanished.

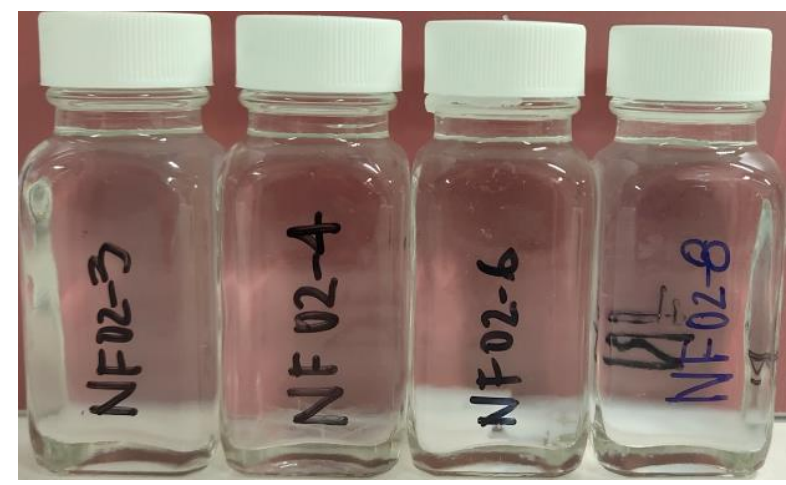

Fig. 6 Visual stability analysis of nanofluids. The white color at the bottom of the ampule shows NPs in the aggregated form. 
Table 5. Permeability and porosity measured before and after nanofluid flooding on core plugs.

\begin{tabular}{|c|c|c|c|c|c|c|c|}
\hline \multirow{2}{*}{ Core } & \multirow{2}{*}{$\begin{array}{c}\text { Injected } \\
\text { nanofluid }\end{array}$} & \multicolumn{3}{|c|}{ Permeability (mD) } & \multicolumn{3}{c|}{ Porosity $^{\mathbf{~}} \mathbf{( \% )}$} \\
\cline { 3 - 8 } & \multirow{2}{*}{$02-3$} & Before & After & \% difference & Before & After & \% difference \\
\hline L1 & 404 & 350 & -13 & 19 & 17 & -10 \\
\hline L2 & 537 & 452 & -16 & 20 & 16 & -19 \\
\hline L3 & \multirow{2}{*}{$02-4$} & 460 & 446 & -3 & 17 & 15 & -11 \\
\hline L4 & & 411 & 370 & -10 & 18 & 16 & -15 \\
\hline L5 & \multirow{2}{*}{$02-6$} & 367 & 232 & -37 & 18 & 13 & -25 \\
\hline L6 & 331 & 246 & -26 & 18 & 14 & -25 \\
\hline L7 & \multirow{2}{*}{$02-8$} & 384 & 292 & -24 & 18 & 15 & -18 \\
\hline L8 & & 265 & 193 & -20 & 20 & 17 & -16 \\
\hline
\end{tabular}

${ }^{2}$ Measured with Helium porosimeter

Based on sedimentation test, it was concluded that NF02-3 and NF02-4 were stable for approximately 4 days whereas NF02-6 and NF02-8 became unstable at $60{ }^{\circ} \mathrm{C}$. The short-term stability of nanofluids would reduce the transport of NPs through porous media and their surface functionalities, thus lowering the economic feasibility at field scale. This draws the conclusion that the surface modification needs to be improved to achieve a long-term stability over a long injection (expected at field-scales). The improvement should not only focus on the NPs stability, but also on the surface chemistry and other possible interactions that may occur between NPs and an oilfield system for better oil recovery.

\subsection{Evaluation of oil recovery}

Evaluation of tertiary oil recovery not only requires the reproducibility of experimental results, but also the proper determination of the waterflood $S_{\text {or }}$ to ensure that any additional oil is solely due to the EOR fluid. To achieve this, twin core plugs were used for each nanofluid type; a bump rate was applied, for $1 \mathrm{PV}$, after waterflood no longer produced oil for 2 PVs during low rate.

The results showed that nanofluids at a concentration of $0.1 \mathrm{wt}$. \% can mobilize residual oil, but it was delayed compared to breakthrough of nanofluids. The arrival of first oil at the core outlet varied among the samples. It occurred within 1.5 to $4 \mathrm{PVs}$. The production due to NF02-6 (Fig. 2b) and NF02-8 was occurred at late injection times compared to other two samples NF02-3 and NF02-4 (Fig. 2a). Most of oil production occurred in the form of small droplets that merged with the oil in the separator. In Fig. 2, the points at which oil recovery increases over time shows the ability of NPs to progressively mobilize residual oil. Large oil production occurred at the expense of large PVs of injected nanofluid, and the late occurrence is partly attributed to differences between the viscosities of nanofluids and crude oil. Additionally, the production was affected by water flood stage and variations in core properties. Therefore, the nanofluids to mobilize the trapped oil, an extra energy was needed. This energy was achieved by physicochemical interactions between NPs and rock system, i.e. deformation and breakage of oil drops and/or NPs blocking enough pores to build up enough pressure within the pores to detach and mobilize the oil in adjacent pores.

Table 3 reports the overall oil recoveries achieved at the end of water- and nanofluid-flooding. The oil recovery achieved by water flood varied from $47.2 \%$ to $56.1 \%$ of OOIP after the flowrate was bumped. When the nanofluid system was injected at low rate, the incremental oil recovery varied from $4.7 \%$ to $11.6 \%$ of OOIP. Increasing the flowrate tenfold, for $\approx 1 \mathrm{PV}$, the ultimate recoveries reached $7.0 \%$ to $14.1 \%$ of OOIP. The oil recovery during the bump rate is shown in Fig. 2 by the "dotted" lines. This was because it was difficult to record the amount of oil produced per step during bump rate, as it was a quick and short process. Additionally, oil was produced as small droplets and could easily be measured at the end of injection. Note that the "dotted" lines in Fig. 2 do not indicate a linear production of oil. The oil production on a bump flood was unexpected as the residual oil is trapped in the pores where high capillary forces prevail. This oil would resist flow even if it is flooded at higher capillary numbers than those present at trapping [33]. In this work, the produced oil indicated that capillary stability was perhaps not reached during low rate and/or the oil trapped in the thin gap between the end core plugs was produced at high flowrate. Future work is recommended to water flood enough to attain the equilibrium before applying EOR fluid injection and mitigate capillary end-effects.

The twin cores produced comparable results; the variation was below $5 \%$ of OOIP. Upscaling the present results for field scale injection is still a challenge. Therefore, one cannot directly compare core scale results to large fields, it may appear economically unfeasible because of the cost of NPs. Research suggests that to better simulate the injections at field-scale, large PVs of nanofluids must be injected at core scale [34]. The results presented in Table 1 and Table 3 show that the highest incremental oil recovery was achieved with the smallest NPs size. The increase in oil recovery with decreasing NP size is consistent with the IFT reduction, see Table 4; small size NPs were efficient in lowering o/w interfacial

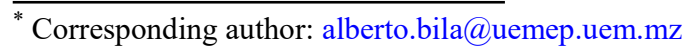


tension, resulting in higher oil recovery than the large sized NPs. These results are in agreement with previous findings reported by others [12, 19], but are also in contrast to the positive correlation observed between the NP size and oil recovery reported by Aurand, et al. [22].

The NPs at 0.1 wt.\% had no plausible effect on the viscosity of the SSW, thus unable to improve the mobility ratio. The maximum differential pressure was achieved from NPs of large size. This supports the notion that increasing NP size decreases the permeability [12], and reduces the surface functionalities of the NPs at the oilwater-rock interfaces $[35,36]$, resulting poor oil recovery.

In summary, the present work proved that polymerfunctionalized silica NPs can EOR efficiently in waterwet waterflooded reservoirs.

\subsection{The EOR mechanisms of nanoparticles}

This work reports promising results on the application of polymer-functionalized silica NPs for EOR. It was noted that various recovery mechanisms can be operating for oil recovery, depending on NP type. This implies that more studies are needed to quantify the contribution of each mechanism involved. The following sections discuss and suggest the underlying oil recovery mechanisms of silica NPs based on our experimental results.

\subsubsection{Interfacial tension and wettability alteration}

Microscopic sweep efficiency can be improved by decreasing capillary forces through lowering oil and water IFT. When injecting NPs, the major expectation is that the differential pressure across the core exceed the capillary forces trapping the oil. This can be achieved if the NPs adsorb to the $\mathrm{o} / \mathrm{w}$ interface and decrease IFT. Capillary number, $\mathrm{N}_{\mathrm{c}}$, describes the balance between the oil mobilizing forces (viscous forces) and the oil trapping forces, and it provides a mean to evaluate how effective the NPs are for EOR.

$$
\mathrm{N}_{\mathrm{c}}=\frac{\mu \nu}{\gamma}
$$

Here, $\mu$ and $\nu$ are the viscosity and velocity of the displacing fluid, respectively, and $\mathrm{\gamma}$ is the interfacial tension between the displacing and displaced phases.

The $\mathrm{N}_{\mathrm{c}}$ for water flooding calculated in this work is of order of $10^{-6}$. It is generally recognized that the critical capillary number for the onset of mobilization of residual oil in water-wet reservoirs is of orders of $\approx 10^{-5}[7,37]$ above which, a complete mobilization of residual may take place. This condition can be met if any additive to the injection fluid, such as NPs, can decrease the IFT between oil and water down to $10^{-3} \mathrm{mN} / \mathrm{m}$ [38].

In this work, it was observed that silica NPs reduced the $\mathrm{o} / \mathrm{w}$ interfacial tension. In Table 4 , one can see that the reduction is modest, this is the IFT values are not low enough to produce enough $\mathrm{N}_{\mathrm{c}}$ for significant mobilization the residual oil. Similar conclusion was reached by other researchers [22, 39]. Furthermore, the results indicate poor surface activity performance of NPs at the $\mathrm{o} / \mathrm{w}$ interface. The reasons for that might be i) the high temperature that increased the degree of collision between the NPs in solution and the aggregation tendency at the $\mathrm{o} / \mathrm{w}$ interface (see Fig. 3); ii) the accumulation (or coating) of polymer molecules on the particle surface could have prevented or reduced the amount of NPs that can move to the oil-water interface [40, 41], thus diminishing particle surface activity. This can occur even under favorable adsorption energy [42]; and iii) the surface modification was lost due to the precipitation of polymers in seawater due to multivalent ions. Furthermore, the aluminum present in composition of the particles (NF02-6 and NF02-8) would form sulphates in solution and prompting the formation of precipitates.

The oil recovery due to NPs relies on both fluid-fluid and fluid-rock interactions. These interactions can modify the fluid distribution and flow-ability of the fluids within the reservoir. To investigate fluid-rock interactions induced by NPs, we explored the rate of water imbibition and the Amott indexes. From Fig. 5, one can see that the rate of water imbibition on NPs treated cores was as high as in original cores (not injected with NPs) from the beginning of the tests, which resulted in significant amount of oil recovery. The oil production was observed from all core faces showing a contribution of both gravity and capillary forces during wettability alteration [43]. Furthermore, in Fig. 5, we see a sudden increase in oil recovery over time from all cores indicating a progressive alteration of rock wettability due to NP exposure on the rock surface. The NPs could destabilize oil films on the surface, rendering the pore spaces more water-wet. At later stage, the oil was produced from top of the cores due to gravity forces. The measured Amott water indexes ranged from 0.5 to 0.86 . There is some variation in the rate of water imbibition and Amott indexes in treated cores compared with original ones and it can be attributed to the retained NPs on the pores and of differences in core properties.

The overall results suggest that wettability was affected by nanofluids to water-wet condition. These results were expected because of hydrophilic nature silica NPs and exposed to a substrate of like surface charge (Berea sandstone). During nanofluid flooding, NPs are forcibly confined to the pre-existing wedge formed between the three-phase water-oil-rock contact line, where they arranged themselves in a well-ordered layer and create an additional disjoining pressure [44], and developing new hydrophilic surface on the pores. The results are in agreement with previous studies $[13,45]$ that studied the wettability alteration using hydrophilic silica nanoparticles. Owing to small effects of NPs on IFT and wettability alteration, the polymer-functionalized silica NPs studied in this work are not expected to increase oil 
recovery by solely reducing the IFT and/or by affecting the wettability. However, the irreversible adsorption of NPs to the o/w interface still plays a predominant role for stabilization of emulsions [20, 25, 46]. The emulsion formation is discussed in the Section 5.3.2.

\subsubsection{Transport of NPs through porous media}

Characterization of transport in the reservoir rocks has two components: the retention and the mobility of the nanoparticle dispersion. The former quantifies the fraction of injected NPs that survive and reach the target zone. The latter defines the operating conditions (e.g. injection pressure and/or flowrate) to bring the injected NPs through the desired pathway and time to the target location [47]. If the differential pressure (dP) across the core is decreasing throughout EOR flooding, it may indicate emulsification of oil [19] otherwise, it indicates microscopic flow diversion due to pore plugging $[4,6]$. This information can lead to an understanding of the EOR mechanisms of NPs flooding.

During the flood of nanofluids NF02-3 and NF02-4, it was observed that $\mathrm{dP}$ increased slightly for $\approx 1 \mathrm{PV}$, then it decreased and levelled to the reference waterflood value (Fig. 7a for NF02-4). The slow rise of dP is thought to be caused by physical confinement of the particles at the core entrance. Then, the pressure levelled relative to the base case as the injection advanced, indicating the ease with which the NPs were propagating through the pore spaces without clogging or causing significant damage to the rock permeability. The reduction of core absolute permeability varied from $3 \%$ to $16 \%$, which confirmed low particle retention on the pore walls. The low injection pressure is likely a manifestation of the role the polymer coating on the NP surface played to improve particle mobility on the pores. Accordingly, this allowed the NPs to stick more to the oil/water interface. From this, we could infer the generation of in-situ emulsions with nanofluid flooding also prompted by flow dynamics and high temperature. This was confirmed by increasing the flowrate and oil-in-water emulsions could be visible in the effluent separator. Increasing the flowrate provided an extra energy required to break up oil phase, thus allowing more NPs to adsorb at the oil-water interface [21]. The generation of emulsions concurs with the reduction of IFT, especially for NF02-3 and NF02-4 (with the lowest IFT reduction among the studied samples). The formed emulsion droplets merged upwards with the oil in the effluent separator within one hour. Earlier studies that investigated the EOR effect of polymer-coated silica NPs, such as those used in this work, have also highlighted the formation of nanoparticles-stabilized emulsions as a mean by which the NPs increased oil recovery increase [13, 20, 25]. It is most likely that samples NF02-3 and NF02-4 improved oil recovery by increasing oil mobility due to generation of stabilized oil-in-water emulsions.
The contrasting results were observed during the injection of samples NF02-6 and NF02-8, little to no emulsions were observed, even at high flowrate. The injection of these samples was accompanied with continuous increased pressure (see Fig. 7b). After 5 PVs of nanofluid injection, $\mathrm{dP}$ showed high degree of oscillation until the tests were stopped. At the end of the floods, a filtered "cake" of NPs was formed at the core inlet (see the inset in Fig. 7b), indicating the occurrence of physical filtration and blockage of the pores.
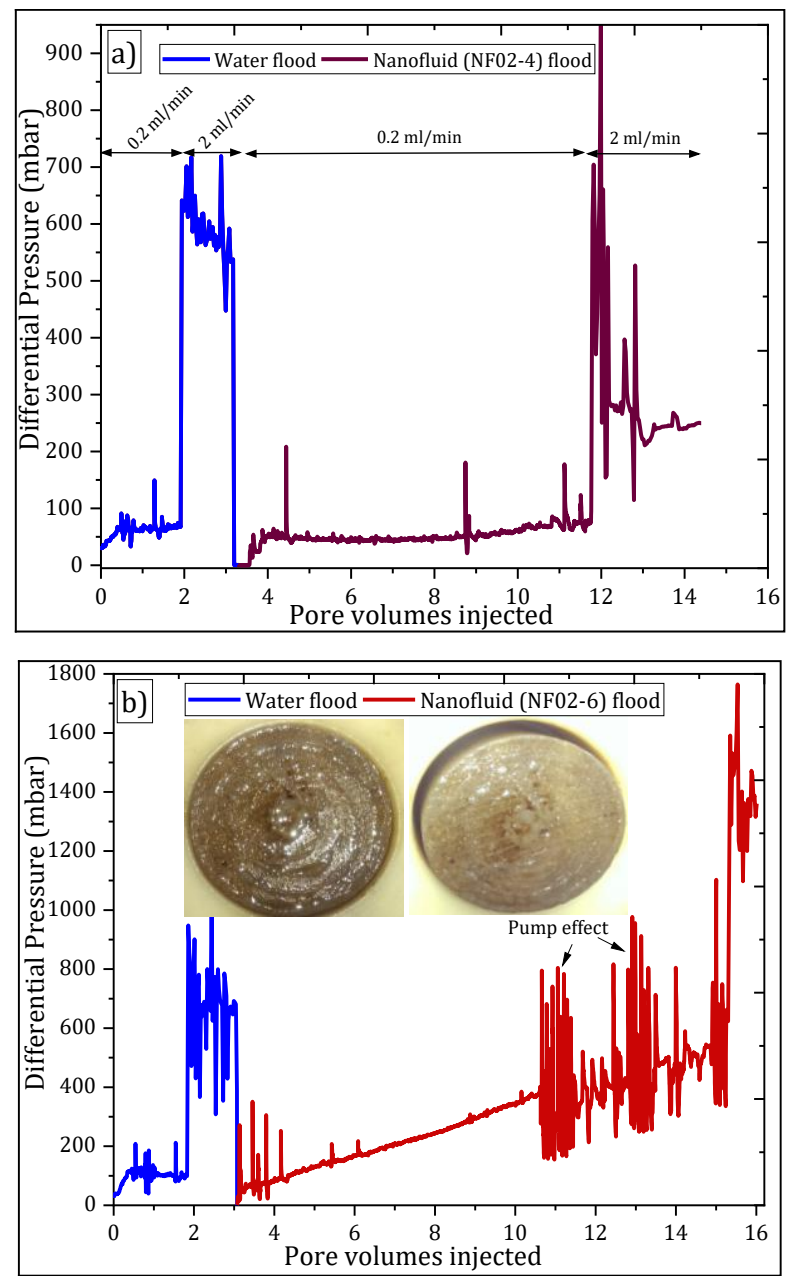

Fig. 7. Differential pressure profiles as a function of PVs of injected fluids: a) NF02-4 injection and b) The inset is the NPs "cake" formed at the core inlet during the injection of NF02-6.

The aggregation at core entrance was expected because were unstable and creating favorable conditions for blockage of small pores from start of the injection. This is likely the primary reason for pressure increase. Consequently, the permeability reduction was in the range of $20 \%$ to $37 \%$ and was higher than that on cores injected with samples NF02-3 and NF02-4. The pressure pattern also indicated that pore plugging was also happening inside the core until an extreme pore blockage was reached. This likely lead to the diversion of the injection water and mobilization of bypassed oil in the adjacent pores. Fig. $\mathbf{7 b}$ also shows periods of an abrupt variation 
of the pressure. These events supported the notion that NPs were further aggregating within the core; as a result, the pressure was redistributed within the pores to assist the injected water to reach the by-passed oil in the adjacent pores and push forward to the core outlet. The pressure was reduced by displacement of the oil and detachment of weakly adsorbed NPs on the pores. This led to the restoration of the normal flow of water. The events of sudden pressure drop in Fig. $\mathbf{7 b}$ reflect such migration behavior of NPs. The blockage continued in the available pore channels. Due to the high pressure generated with advancing of the injection and subsequent confinement of NPs in the pores, the oil was detached from the surface and produced before the pores were relocked. However, the pressure increase was not always accompanied by oil production.

The primary recovery mechanisms for NF02-6 and NF02-8 is possibly through microscopic flow diversion also referred to as log-jamming effect [6, 7, 22]. According to Spildo, et al. [4] and Skauge, et al. [6] this phenomenon can be explained by mass difference between the NPs and water. The NPs in aqueous solution carry water molecules, which decreases their flow ability, hence causing the particles to accumulate at the pore entrance. This concurs with our results because the NPs were aggregating in SSW solution before injection.

Due to the synergistic effect of IFT reduction and wetting effect, the high $\mathrm{dP}$ is believed to have contributed in the mobilization of both by-passed and capillarytrapped oil. Quantifying the contribution of pore blocking and fluid flow diversion mechanisms in the mobilization of oil based on differential pressure is complex because pressure fluctuation.

\subsection{Effect of NPs on permeability and porosity}

To evaluate the influence of NPs on rock properties, permeability and porosity were evaluated and compared with initial values. The results are presented in Table 5. The permeability and porosity decreased relative to initial values. The cores injected with nanofluids containing small-sized NPs diameter (NF02-3 and NF02-4) resulted in the lowest permeability and porosity reduction in the range of $3 \%$ to $16 \%$ and from $10 \%$ to $19 \%$, respectively. For these samples the particle retention may be due to chemical adsorption of NPs owing to their small size [11] and composition. The slightly high values of porosity reduction suggested that adsorption and blockage due to NPs were relevant in the large pores. As expected, large size particles gave the largest permeability and porosity impairments. The permeability reduction was from $20 \%$ to $37 \%$ and from $16 \%$ to $25 \%$ for the porosity. Because the NPs aggregated in SSW, significant permeability and porosity reductions were expected. It is likely that the measurements were affected by core preparation steps for wettability evaluation post nanofluid flood.

\section{Conclusions}

In this work, a series of flooding experiments were conducted to investigate to unleash the EOR potential of four different types of polymer-functionalized silica NPs on water-wet Berea sandstone cores at $60{ }^{\circ} \mathrm{C}$. The underlying EOR mechanisms of the NPs were also investigated. The following conclusions were obtained:

- The core flooding studies demonstrated that silica nanoparticles coated with polymer chains can effectively mobilize residual oil and increase oil recovery. The incremental oil recovery ranged from 7 to $14 \%$ of OOIP;

- The IFT between water and oil was decreased with modified silica NPs, but the reduction is not in orders of magnitude to contribute significantly for the remobilization of residual oil;

- The nanoparticles caused variation of the Berea sandstone surface structure, thus affecting the wettability towards water-wet condition;

- Aside from IFT reduction and wettability alteration, nanofluids NF02-3 and NF02-4 increased the mobility of trapped oil by creating oil droplets emulsions, while pore blocking, and microscopic flow diversion was relevant mechanism for samples NF02-6 and NF02-8.

Further work includes improving evaluation procedure of oil recovery as well as recovery mechanisms of the nanoparticles in neutral-wet reservoirs.

Acknowledgements: The authors gratefully acknowledge Evonik Industries for providing the nanoparticles used in this work and the Research Council of Norway for their financial support through PoreLab, Centre of Excellence, project number 262644.

\section{References}

[1] X. Sun, Y. Zhang, G. Chen, and Z. Gai, "Application of Nanoparticles in Enhanced Oil Recovery: A Critical Review of Recent Progress," Energies, vol. 10(3), 2017.

[2] A. Muggeridge et al., "Recovery rates, enhanced oil recovery and technological limits," Philosophical transactions. Series A, Mathematical, physical, and engineering sciences, vol. 372(2006), 2014, pp. 20120320-20120320.

[3] I. Sandrea and R. Sandrea, "Recovery factors leave vast target for EOR technologies," Oil \& Gas Journal, vol. 105(41), 2007, pp. 44-47.

[4] K. Spildo, A. Skauge, M. G. Aarra, and M. T. Tweheyo, "A New Polymer Application for North Sea Reservoirs," SPE Reservoir Evaluation \& Engineering, vol. 12(03), 2009, pp. 427-432.

[5] M. A. E. Kokubun, F. A. Radu, E. Keilegavlen, K. Kumar, and K. Spildo, "Transport of Polymer Particles in Oil-Water Flow in Porous Media: Enhancing Oil Recovery," Transport in Porous Media, vol. 126(2), 2018, pp. 501-519. 
[6] T. Skauge, K. Spildo, and A. Skauge, "Nano-sized Particles For EOR," in SPE Improved Oil Recovery Symposium, Tulsa, Oklahoma, USA, 2010, pp. 10. https://doi.org/10.2118/129933-MS.

[7] Z. Hu, S. M. Azmi, G. Raza, P. W. J. Glover, and D. Wen, "Nanoparticle-assisted water-flooding in Berea sandstones," Energy \& Fuels, vol. 30(4), 2016, pp. 2791-2804.

[8] S. Ayatollahi and M. M. Zerafat, "NanotechnologyAssisted EOR Techniques: New Solutions to Old Challenges," in SPE International Oilfield Nanotechnology Conference and Exhibition, Noordwijk, The Netherlands, 2012, pp. 15. https://doi.org/10.2118/157094-MS.

[9] M. V. Bennetzen and K. Mogensen, "Novel Applications of Nanoparticles for Future Enhanced Oil Recovery," in International Petroleum Technology Conference, Kuala Lumpur, Malaysia, 2014, pp. 14. https://doi.org/10.2523/IPTC-17857MS.

[10] M. I. Youssif, R. M. El-Maghraby, S. M. Saleh, and A. Elgibaly, "Silica nanofluid flooding for enhanced oil recovery in sandstone rocks," Egyptian Journal of Petroleum, vol. 27(1), 2018, pp. 105-110.

[11] M. Zallaghi, R. Kharrat, and A. Hashemi, "Improving the microscopic sweep efficiency of water flooding using silica nanoparticles," Journal of Petroleum Exploration and Production Technology, vol. 8(1), 2018, pp. 259-269.

[12] L. Hendraningrat, S. Li, and O. Torsater, "Effect of Some Parameters Influencing Enhanced Oil Recovery Process using Silica Nanoparticles: An Experimental Investigation," in SPE Reservoir Characterization and Simulation Conference and Exhibition, Abu Dhabi, UAE, 2013, pp. 10. https://doi.org/10.2118/165955-MS.

[13] B. A. Suleimanov, F. S. Ismailov, and E. F. Veliyev, "Nanofluid for enhanced oil recovery," Journal of Petroleum Science and Engineering, vol. 78(2), 2011, pp. 431-437.

[14] K. Xu, D. Agrawal, and Q. Darugar, "Hydrophilic Nanoparticle-Based Enhanced Oil Recovery: Microfluidic Investigations on Mechanisms," Energy \& Fuels, vol. 32(11), 2018, pp. 1124311252.

[15] N. A. Ogolo, O. A. Olafuyi, and M. O. Onyekonwu, "Enhanced Oil Recovery Using Nanoparticles," in SPE Saudi Arabia Section Technical Symposium and Exhibition, Al-Khobar, Saudi Arabia, 2012, pp. 9. https://doi.org/10.2118/160847-MS.

[16] L. Hendraningrat, S. Li, and O. Torsæter, "A coreflood investigation of nanofluid enhanced oil recovery," Journal of Petroleum Science and Engineering, vol. 111(2013, pp. 128-138.

[17] A. Bila, A. J. Stensen, and O. Torsæter, "Experimental Investigation of Polymer-Coated Silica Nanoparticles for Enhanced Oil Recovery," Nanomaterials, vol. 9(6), 2019.

[18] R. Li, P. Jiang, C. Gao, F. Huang, R. Xu, and X. Chen, "Experimental Investigation of Silica-Based Nanofluid Enhanced Oil Recovery: The Effect of
Wettability Alteration," Energy \& Fuels, vol. 31(1), 2017, pp. 188-197.

[19] M. Adil, K. Lee, H. M. Zaid, N. R. A. Latiff, and M. S. Alnarabiji, "Experimental study on electromagnetic-assisted $\mathrm{ZnO}$ nanofluid flooding for enhanced oil recovery (EOR)," PloS one, vol. 13(2), 2018, pp. e0193518.

[20] T. Zhang, D. Davidson, S. L. Bryant, and C. Huh, "Nanoparticle-Stabilized Emulsions for Applications in Enhanced Oil Recovery," in SPE Improved Oil Recovery Symposium, Tulsa, Oklahoma, USA, 2010, pp. 18. https://doi.org/10.2118/129885-MS.

[21] I. Kim, A. J. Worthen, K. P. Johnston, D. A. DiCarlo, and C. Huh, "Size-dependent properties of silica nanoparticles for Pickering stabilization of emulsions and foams," Journal of Nanoparticle Research, vol. 18(4), 2016, pp. 82.

[22] K. R. Aurand, G. S. Dahle, and O. Torsæter, "Comparison of oil recovery for six nanofluids in Berea sandstone cores," in International Symposium of the SCA, France, 2014, vol., no., pp. 1-12.

[23] A. I. El-Diasty and A. M. Aly, "Understanding the Mechanism of Nanoparticles Applications in Enhanced Oil Recovery," in SPE North Africa Technical Conference and Exhibition, Cairo, Egypt, 2015, pp. 19. https://doi.org/10.2118/175806-MS.

[24] A. Bila, J. Å. Stensen, and O. Torsæter, "Experimental Evaluation of Oil Recovery Mechanisms Using a Variety of Surface-Modified Silica Nanoparticles in the Injection Water," in SPE Norway One Day Seminar, Bergen, Norway, 2019, pp. 19. https://doi.org/10.2118/195638-MS.

[25] H. ShamsiJazeyi, C. A. Miller, M. S. Wong, J. M. Tour, and R. Verduzco, "Polymer-coated nanoparticles for enhanced oil recovery," Journal of Applied Polymer Science, vol. 131(15), 2014.

[26] A. O. Gbadamosi, R. Junin, M. A. Manan, N. Yekeen, A. Agi, and J. O. Oseh, "Recent advances and prospects in polymeric nanofluids application for enhanced oil recovery," Journal of Industrial and Engineering Chemistry, vol. 66(2018, pp. 1-19.

[27] N. K. Maurya and A. Mandal, "Studies on behavior of suspension of silica nanoparticle in aqueous polyacrylamide solution for application in enhanced oil recovery," Petroleum Science and Technology, vol. 34(5), 2016, pp. 429-436.

[28] R. Ponnapati, O. Karazincir, E. Dao, R. Ng, K. K. Mohanty, and R. Krishnamoorti, "Polymerfunctionalized nanoparticles for improving waterflood sweep efficiency: Characterization and transport properties," Industrial \& Engineering Chemistry Research, vol. 50(23), 2011, pp. 1303013036.

[29] A. Behzadi and A. Mohammadi, "Environmentally responsive surface-modified silica nanoparticles for enhanced oil recovery," Journal of Nanoparticle Research, vol. 18(9), 2016, pp. 266.

[30] S. K. Choi, H. A. Son, H. T. Kim, and J. W. Kim, "Nanofluid enhanced oil recovery using hydrophobically associative zwitterionic polymer- 
coated silica nanoparticles," Energy \& Fuels, vol. 31(8), 2017, pp. 7777-7782.

[31] W. G. Anderson, "Wettability Literature Survey Part 5: The Effects of Wettability on Relative Permeability," Journal of Petroleum Technology, vol. 39(11), 1987, pp. 1453-1468.

[32] R. S. Seright, A. Campbell, P. Mozley, and P. Han, "Stability of Partially Hydrolyzed Polyacrylamides at Elevated Temperatures in the Absence of Divalent Cations," SPE Journal, vol. 15(02), 2010, pp. 341348.

[33] C. A. McPhee and K. G. Arthur, "Relative permeability measurements: an inter-laboratory comparison," in, vol., no.: Society of Petroleum Engineers, pp.

[34] K. H. Hosseinzade and O. Torsæter, Injected pore volume on lab and field scales (9th International Conference on Porous Media \& Annual Meeting). Rotterdam, Netherlands: International Society for Porous Media, Interpore, (2017).

[35] A. Habibi, M. Ahmadi, P. Pourafshary, s. Ayatollahi, and Y. Al-Wahaibi, "Reduction of Fines Migration by Nanofluids Injection: An Experimental Study," SPE Journal, vol. 18(02), 2012, pp. 309318.

[36] P. Bacchin, Q. Derekx, D. Veyret, K. Glucina, and P. Moulin, "Clogging of microporous channels networks: role of connectivity and tortuosity," Microfluidics and Nanofluidics, vol. 17(1), 2014, pp. 85-96.

[37] K. J. Humphry, B. M. J. M. Suijkerbuijk, H. A. van der Linde, S. G. J. Pieterse, and S. K. Masalmeh, "Impact of Wettability on Residual Oil Saturation and Capillary Desaturation Curves," Petrophysics, vol. 55(04), 2014, pp. 313-318.

[38] J. J. Sheng, "Status of surfactant EOR technology," Petroleum, vol. 1(2), 2015, pp. 97-105.

[39] C. Dai et al., "Spontaneous Imbibition Investigation of Self-Dispersing Silica Nanofluids for Enhanced Oil Recovery in Low-Permeability Cores," Energy \& Fuels, vol. 31(3), 2017, pp. 2663-2668.

[40] X. Zhang, M. R. Servos, and J. Liu, "Ultrahigh Nanoparticle Stability against Salt, $\mathrm{pH}$, and Solvent with Retained Surface Accessibility via Depletion Stabilization," Journal of the American Chemical Society, vol. 134(24), 2012, pp. 9910-9913.

[41] W. Kuang, S. Saraji, and M. Piri, "A systematic experimental investigation on the synergistic effects of aqueous nanofluids on interfacial properties and their implications for enhanced oil recovery," Fuel, vol. 220(2018, pp. 849-870.

[42] V. N. Paunov, B. P. Binks, and N. P. Ashby, "Adsorption of charged colloid particles to charged liquid surfaces," Langmuir, vol. 18(18), 2002, pp. 6946-6955.

[43] M. Mohammed and T. Babadagli, "Wettability alteration: A comprehensive review of materials/methods and testing the selected ones on heavy-oil containing oil-wet systems," Advances in colloid and interface science, vol. 220(2015, pp. 5477.
[44] D. T. Wasan and A. D. Nikolov, "Spreading of nanofluids on solids," Nature, vol. 423(6936), 2003, pp. 156-159.

[45] S. Li and O. Torsaeter, "The Impact of Nanoparticles Adsorption and Transport on Wettability Alteration of Intermediate Wet Berea Sandstone," in SPE Middle East Unconventional Resources Conference and Exhibition, Muscat, Oman, 2015, pp. 14. https://doi.org/10.2118/172943-MS.

[46] D. A. DiCarlo, B. Aminzadeh, M. Roberts, D. H. Chung, S. L. Bryant, and C. Huh, "Mobility control through spontaneous formation of nanoparticle stabilized emulsions," Geophysical Research Letters, vol. 38(24), 2011.

[47] E. Rodriguez Pin, M. Roberts, H. Yu, C. Huh, and S. L. Bryant, "Enhanced Migration of Surface-Treated Nanoparticles in Sedimentary Rocks," in SPE Annual Technical Conference and Exhibition, New Orleans, Louisiana, 2009, pp. 21. https://doi.org/10.2118/124418-MS. 